\title{
Robust Biofilm-Forming Bacillus Isolates from the Dairy Environment Demonstrate an Enhanced Resistance to Cleaning-in-Place Procedures
}

\author{
Ievgeniia Ostrov ${ }^{1,2}$, Tali Paz $^{1}$ and Moshe Shemesh ${ }^{1, *}$ \\ 1 Department of Food Sciences, Institute for Postharvest Technology and Food Sciences, Agricultural Research \\ Organization (ARO), The Volcani Center, 7528809 Rishon LeZion, Israel; \\ ievgenia.ostrov@mail.huji.ac.il (I.O.); talipaz@agri.gov.il (T.P.) \\ 2 The Hebrew University-Hadassah, 9112001 Jerusalem, Israel \\ * Correspondence: moshesh@agri.gov.il; Tel.: +972-39683868
}

Received: 27 January 2019; Accepted: 16 April 2019; Published: 20 April 2019

\begin{abstract}
One of the main strategies for maintaining the optimal hygiene level in dairy processing facilities is regular cleaning and disinfection, which is incorporated in the cleaning-in-place (CIP) regimes. However, a frail point of the CIP procedures is their variable efficiency in eliminating biofilm bacteria. In the present study, we evaluated the susceptibility of strong biofilm-forming dairy Bacillus isolates to industrial cleaning procedures using two differently designed model systems. According to our results, the dairy-associated Bacillus isolates demonstrate a higher resistance to CIP procedures, compared to the non-dairy strain of B. subtilis. Notably, the tested dairy isolates are highly persistent to different parameters of the CIP operations, including the turbulent flow of liquid (up to $1 \mathrm{log}$ ), as well as the cleaning and disinfecting effects of commercial detergents (up to $2.3 \mathrm{log}$ ). Moreover, our observations indicate an enhanced resistance of poly- $\gamma$-glutamic acid (PGA)-overproducing B. subtilis, which produces high amounts of proteinaceous extracellular matrix, to the CIP procedures (about $0.7 \mathrm{log}$, compared to the wild-type non-dairy strain of B. subtilis). We therefore suggest that the enhanced resistance to the CIP procedures by the dairy Bacillus isolates can be attributed to robust biofilm formation. In addition, this study underlines the importance of evaluating the efficiency of commercial cleaning agents in relation to strong biofilm-forming bacteria, which are relevant to industrial conditions. Consequently, we believe that the findings of this study can facilitate the assessment and refining of the industrial CIP procedures.
\end{abstract}

Keywords: dairy industry; biofilm; Bacillus species; biofilm derived spores; cleaning-in-place; disinfecting effect

\section{Introduction}

Microbial contamination, caused by biofilm-forming bacteria, is one of the main threats to the quality, safety, stability and nutritional value of dairy products [1,2]. Moreover, biofilms are not only a potential source of contamination; they can also increase the corrosion rate of equipment used in the milk industry, impair heat transfer, and increase fluid frictional resistance [3]. Therefore, controlling biofilm formation is of major importance to the dairy industry [4-6].

Members of the Bacillus genus are among the most commonly found biofilm-formers in dairy farms and processing plants [7-9]. In addition to aggressive biofilm, these bacteria are able to form heat-resistant endospores $[10,11]$. To this end, the biofilm matrix can serve as an epicenter for the ripening of spores, which can be released from it and cause continuous contamination of the production environment $[12,13]$. Spores, as well as biofilm cells, are highly resistant to antimicrobial agents, which makes it rather difficult to eliminate them [11,14]. Moreover, biofilm matrix offers additional 
protection for embedded endospores, allowing their survival and colonization in the surrounding environment, when conditions are favorable [15]. In B. subtilis, the matrix has two main components, an exopolysaccharide (EPS) and amyloid-like fibers. Another extracellular polymer, $\gamma$-poly-DL-glutamic acid (PGA), is produced in copious amounts by some B. subtilis strains [16-18].

The main strategy to prevent biofilm formation, applied in the dairy industry, is to clean and disinfect regularly before bacteria attach firmly to surfaces $[19,20]$. Cleaning and disinfection in dairy processing plants have been incorporated into the cleaning-in-place (CIP) regimes, which include regular cleaning of processing equipment with alkaline and acidic liquids at high temperatures and flow velocities [4,21,22]. However, a weak point of CIP processes, evident in both industrialand laboratory-scale systems, is their variable efficiency in eliminating established biofilms [4,21,23]. It is conceivable that biofilm formation can facilitate bacterial adaptation and survival in certain environmental niches. We therefore hypothesized that aggressive biofilm formation by dairy-associated bacteria might increase their resistance to industrial cleaning procedures.

In the present study, we evaluated the susceptibility of strong biofilm-forming dairy Bacillus isolates to cleaning-in-place procedures using two different model systems, which resemble industrial cleaning conditions. Our results show that the dairy-associated Bacillus isolates demonstrate enhanced resistance to different aspects of the CIP procedures, including mechanical, chemo-biological and disinfecting effects. Such reduced susceptibility can be attributed to robust biofilm formation by the tested dairy Bacillus.

\section{Materials and Methods}

\subsection{Bacterial Strains and Growth Conditions}

The following bacterial strains were used in this study: (i) dairy-associated isolates, such as B. paralicheniformis S127 [24,25], B. licheniformis MS310, B. subtilis MS302, B. paralicheniformis MS303 [24]; (ii) non-dairy isolate B. subtilis NCIB3610 (descendant of B. subtilis Marburg); (iii) poly- $\gamma$-glutamic acid (PGA)-overproducing mutant derivatives of B. subtilis 3610, B. subtilis YC295 ( $\triangle y w c C$ ) and B. subtilis YY54 ( $\Delta p g d S$ ) (a gift of Y. Chai [18]). B. licheniformis MS310, B. subtilis MS302 and B. paralicheniformis MS303 whole-genome shotgun projects are deposited at DDBJ/EMBL/GenBank, under accession numbers MIPQ00000000, MIZD00000000, MIZE00000000 respectively.

For routine growth, the strains were propagated in Lysogeny broth (LB; $10 \mathrm{~g}$ tryptone, $5 \mathrm{~g}$ yeast extract, $5 \mathrm{~g} \mathrm{NaCl}$ per liter, $\mathrm{pH} 7$ ) or on a solidified LB medium, supplemented with $1.5 \%$ agar at $37^{\circ} \mathrm{C}$.

\subsection{Generation of Biofilm-Derived Spores}

Biofilm colonies were generated at $30{ }^{\circ} \mathrm{C}$ in a biofilm-promoting medium (LBGM $=\mathrm{LB}+1 \% v / v$ glycerol $+0.1 \mathrm{mM} \mathrm{MnSO}_{4}$ ) [26]. Biofilm-derived spores were obtained from colonies, as described previously [21]. Briefly, the grown (three-day-old) colonies, harvested and suspended in phosphate buffered saline (PBS; $0.01 \mathrm{M}$ phosphate buffer, $0.0027 \mathrm{M} \mathrm{KCl}, 0.137 \mathrm{M} \mathrm{NaCl}$ per $200 \mathrm{~mL}$, Sigma Aldrich, St. Louis, MO, USA), were disrupted by mild sonication (Vibra Cell, Sonics, Newtown, CT, USA; amplitude $60 \%$, pulse $10 \mathrm{~s}$, pause $10 \mathrm{~s}$, duration $2 \mathrm{~min}$, instrument power: 7.2 Joules per second). During sonication, the samples were kept on ice. Then, heat killing was performed at $80^{\circ} \mathrm{C}$ for $20 \mathrm{~min}$. Cell numbers after heat killing were quantified by the spread plating method.

\subsection{Staining Extracellular Matrix of Biofilm-Derived Spores}

Biofilm-derived spores were stained using the FilmTracer ${ }^{\mathrm{TM}}$ SYPRO ${ }^{\circledR}$ Ruby Biofilm Matrix Stain (Molecular Probes, Eugene, OR, USA), according to the manufacturer's protocol. Stained samples were visualized by confocal laser scanning microscopy (CLSM; Olympus IX81, Tokyo, Japan) at a $10 \mu \mathrm{m}$ scale. 


\subsection{Preparation for Cleaning Tests and Enumeration of Biofilm-Derived Spores}

The preparation of biofilm-derived spores for cleaning tests was performed, as described in the previous study [21]. Briefly, 200- $\mu \mathrm{L}$ aliquots of the spore suspension (containing approximately two million spores) were applied in the sampling area of stainless-steel sampling plates and dried in a biological laminar hood for $1 \mathrm{~h}$. Two sampling plates were not exposed to the cleaning procedures (control). Following each cleaning test, the sampling plates were immediately subjected to abundant rinsing with tap water at RT (similar to the CIP procedures at Israeli dairy farms, where the rinsing with water stage is introduced after applying a cleaning agent). For the enumeration of the spores, the sampling area on each plate was carefully swabbed with cotton swabs, moistened in PBS buffer. Swabs from each plate were then agitated in PBS in separate test tubes. Serial dilutions from each sample were prepared, followed by spread plating on LB agar for CFU analysis. Plates were incubated for $24 \mathrm{~h}$ at $37^{\circ} \mathrm{C}$, before the colonies were counted. The efficiency of a cleaning procedure was evaluated by comparing the number of viable spores (attached to sampling plates), before and after cleaning.

\subsection{Cleaning Solutions}

The following cleaning solutions were used in this study: Caustic soda $(\mathrm{NaOH})$, sodium hypochlorite $(\mathrm{NaOCl})$ and six different commercial alkaline detergents, defined as solutions I (10-15\% NaOH, 3-5\% $\mathrm{NaOCl}), \mathrm{A}$ (polycarboxylate, phosphates, $3.6 \% \mathrm{NaOCl}), \mathrm{M}(>5 \%$ polycarboxylate, $5-15 \%$ phosphates, $3.6 \% \mathrm{NaOCl}), \mathrm{F}$ ( $5 \%$ phosphonates, polycarboxylates), $\mathrm{D}$ (active chlorine, alkaline-based) and $\mathrm{H}$ (active chlorine, phosphates, additives, alkaline-based), which are commonly used in the Israeli dairy farms. The $\mathrm{pH}$ value of the tested solutions varied between 11-12; the $\mathrm{pH}$ of $\mathrm{NaOH}$ was 13; and the $\mathrm{pH}$ of $\mathrm{NaOCl}$ was 4 . In accordance with the manufacturer's recommendations, the agents were used at the following concentrations: (i) $0.5 \%(v / v)$ for solutions A, M, F, D, H; (ii) $0.6 \%(v / v)$ for solution I; (iii) $0.5 \%$ $(\mathrm{m} / \mathrm{v})$ for caustic soda and detergent $\mathrm{H}$; (iv) $0.018 \%(\mathrm{v} / \mathrm{v})$ for sodium hypochlorite (similar to the $\mathrm{NaOCl}$ concentration in working solutions of the examined cleaning agents, such as $\mathrm{A}, \mathrm{M}$ and I). As a control, tap water was used ( $\mathrm{pH}$ value around 7.7), with a standard level of hardness $\left(50 \mathrm{mg} / \mathrm{L} \mathrm{Ca}{ }^{2+}, 50 \mathrm{mg} / \mathrm{L}\right.$ $\left.\mathrm{Mg}^{2+}\right)$, without the addition of any detergent.

\subsection{Cleaning Test Installations}

The cleaning tests were carried out either using the cleaning-in-place (CIP) model system (closely resembling the typical conditions for milking systems) [21] or using the simplified laboratory procedure, developed in this study.

\subsubsection{CIP Model System}

The main components of the CIP model system were described in the previous study [21]. In brief, the system consists of a 5-m stainless-steel milk line (fitted with a test unit) for pumping the cleaning agents from the basin, milk releaser, and a stainless-steel return line to the basin. The test unit has T-junctions, protruding 35, 125 or $275 \mathrm{~mm}$ from the main loop, reflecting different degrees of cleaning difficulty. Sampling plates with the spores were mounted on the T-junctions and cleaned in the installation. The temperature of the cleaning solution during the cleaning tests was $50^{\circ} \mathrm{C}$. To generate flushing pulsation of the circulating liquid, air was introduced into the system every $8 \mathrm{~s}$. The duration of each cleaning cycle was $10 \mathrm{~min}$.

\subsubsection{Laboratory System}

For cleaning tests in the laboratory system, sampling plates with the spores were placed into $100 \mathrm{~mL}$ plastic vessels (Yoel Naim, Rehovot, Israel), containing $50 \mathrm{~mL}$ of cleaning solution (preliminarily warmed to $50{ }^{\circ} \mathrm{C}$ ). The samples were incubated in closed vessels at conditions simulating those in the CIP-model system $\left(50^{\circ} \mathrm{C}, 250 \mathrm{rpm}\right)$ for $10 \mathrm{~min}$. 


\subsection{Evaluation of the Effect of the Cleaning Agents on the Viability of Bacillus Spores}

The tested solutions were added to spore suspension within tap water containing around $1 \times 10^{7} \mathrm{CFU} / \mathrm{mL}$ spores. The spore suspension without the addition of detergents was used as a control. The samples were incubated in closed tubes under the conditions of the laboratory system $\left(50^{\circ} \mathrm{C}, 250 \mathrm{rpm}\right)$ for $10 \mathrm{~min}$. The CFU measurements of the number of viable spores were made immediately after the addition of the tested cleaning agents and following $10 \mathrm{~min}$ of incubation.

\subsection{Statistical Analysis}

The results of the study are the means and standard deviation (SD) of at least two independent biological experiments, performed in triplicate. The Student's $t$ test was used to calculate the significance of the difference between the mean expression of a given experimental sample and the control sample. A $p$ value of $<0.05$ was considered significant.

\section{Results}

\subsection{Dairy-Associated Bacillus Isolates Exhibit Robust Biofilm Phenotype Compared to B. subtilis 3610}

We focused this investigation on biofilm-forming milk isolates of Bacillus species, which were obtained from Israeli dairy farms and recently identified and characterized [24]. The isolates were further characterized using a colony-type biofilm model for the robustness of their biofilm-forming capabilities (Figure 1; Table S1). We found notable differences in the colony-biofilm phenotype between B. subtilis 3610 and the dairy Bacillus isolates (Figure 1A). Thus, the biofilm colonies of B. subtilis 3610 had a complex "wrinkled" structure (shown to be a network of channels rich in biofilm matrix-producing cells $[27,28])$, but were not mucoid. The colonies of the tested dairy-associated strains combined an intricate "wrinkled" phenotype with the formation of highly mucoid "channel"- and "ridge"-like structures, not observed for B. subtilis 3610 (Figure 1A).

To support this observation, we analyzed the extracellular matrix content in the colony biofilm of the tested dairy Bacillus isolates and B. subtilis 3610 by visualizing matrix proteins. Our results indicate that biofilm cells/spores, harvested from colonies of the dairy-associated strains, could be surrounded by higher amounts of extracellular polymeric substances (EPS), compared to B. subtilis 3610 (Figure 1B). 
A

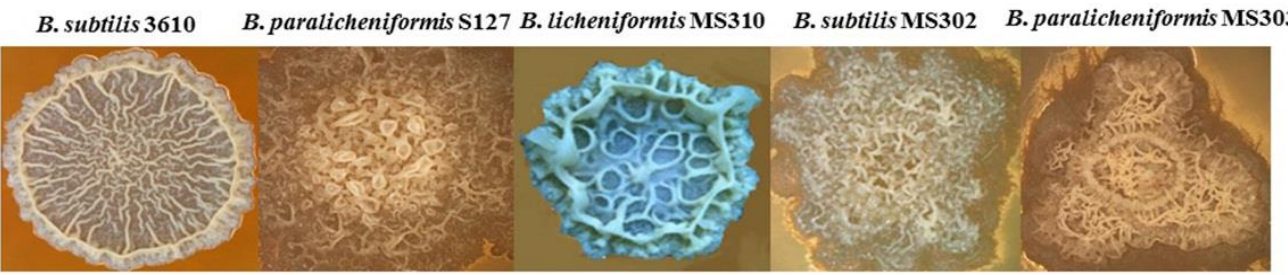

B

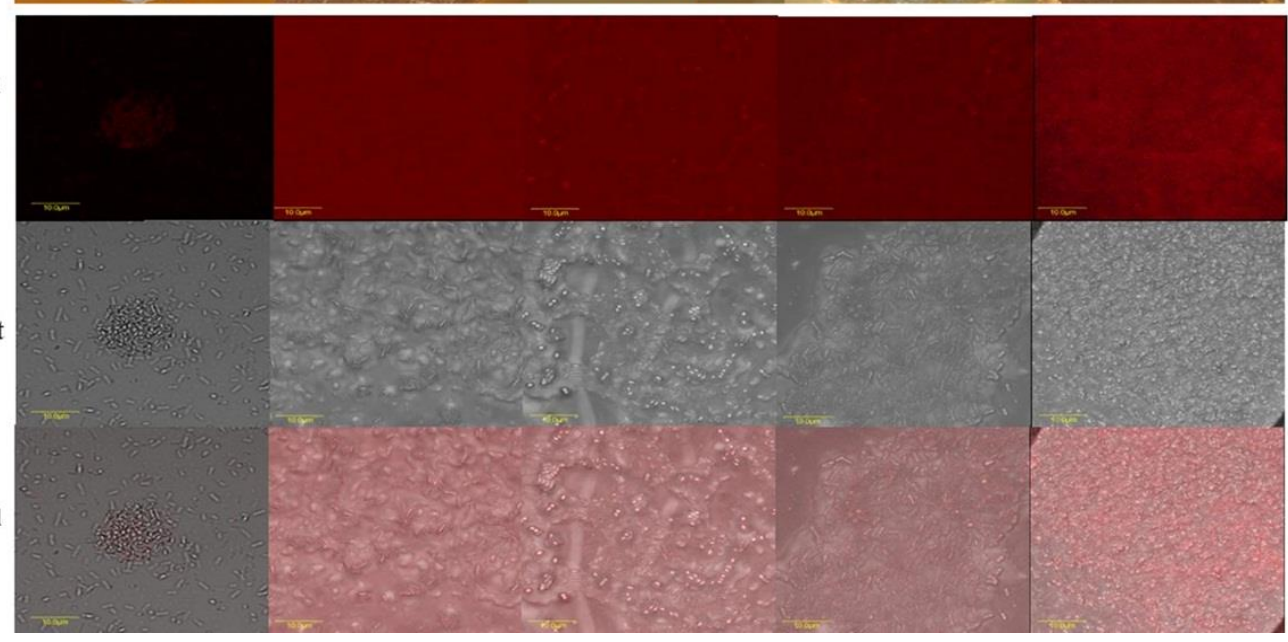

Figure 1. Dairy-associated Bacillus isolates exhibit robust biofilm formation. (A) Colony type biofilm formation by the tested Bacillus strains in the biofilm-promoting medium, LBGM. The images were taken using a stereoscopic microscope (Zeiss Stemi 2000-C; Carl Zeiss, Gottingen, Germany). (B) Biofilm-derived spores of the dairy Bacillus strains are surrounded by high amounts of the extracellular matrix. Protein components of the biofilm matrix were stained red. The samples were analyzed using a confocal laser scanning microscope (CSLM, Olympus, Japan). Scale: $10 \mu \mathrm{m}$.

\subsection{Dairy-Associated Bacillus Isolates Display an Enhanced Resistance to the Mechanical Effect of} Water Circulation

Primarily, we evaluated the susceptibility of the tested strains to water circulation in the CIP model system (closely resembling the conditions typical for milking pipes). Cleaning with water alone reflects the mechanical cleaning effect brought about by the flow of liquid in the installation [21,29]. The susceptibility of the dairy-associated Bacillus strains to cleaning procedures was compared to the non-dairy isolate B. subtilis 3610 (used as a model strain in our previous study [20]). In order to simulate dairy biofilm, we used a system that is based on the biofilm-derived spores of the tested Bacillus, obtained from the biofilm colonies as previously described [21].

We found that the biofilm-derived spores of the dairy Bacillus were significantly (by 0.3-1 log) more resistant to water circulation, compared to B. subtilis 3610, in the case of 35 and $125 \mathrm{~mm}$ T-junctions (representing high levels of turbulence; Figure 2). In the samples placed into the 275-mm T-junctions (the lowest degree of turbulence available in the CIP model system), the susceptibility to cleaning was either similar (B. paralicheniformis S127) or lower by 0.1-0.3 log (B. paralicheniformis MS303, B. licheniformis MS310, B. subtilis MS302) than the control samples. 


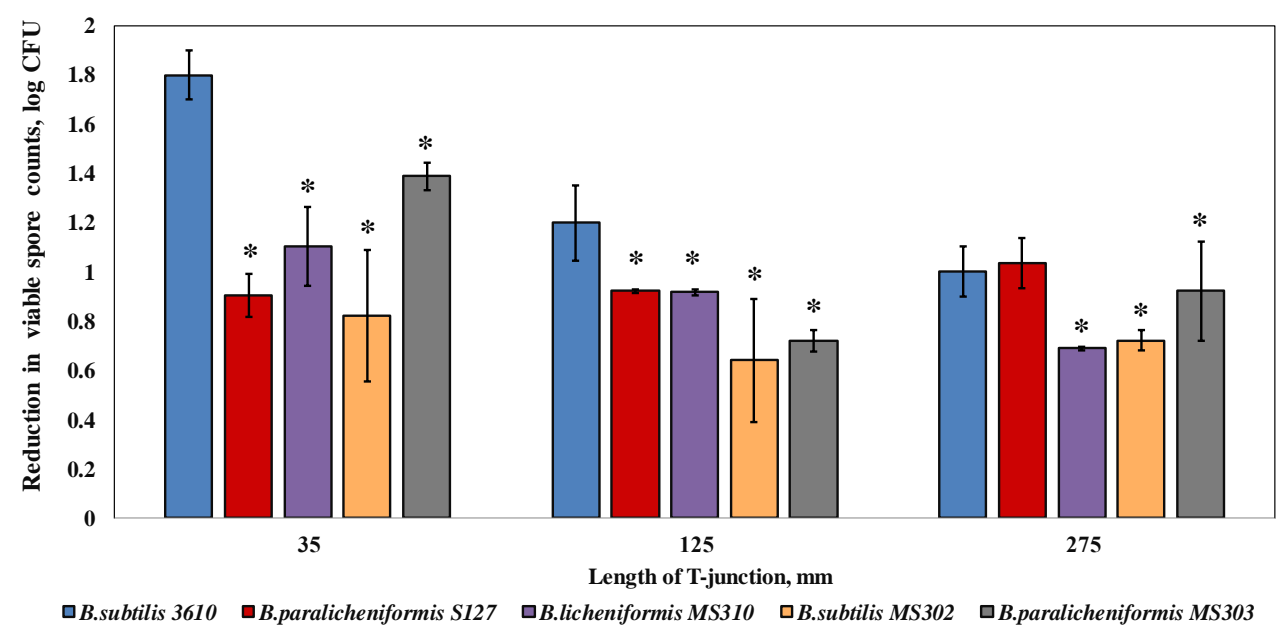

Figure 2. Effect of the cleaning procedure with tap water on the removal of biofilm-derived spores of the dairy-associated Bacillus in the CIP model system. Sampling plates, each containing approximately 2 million spores of B. subtilis 3610 or dairy Bacillus isolates, were mounted on T-junctions, protruding 35,125 , and $275 \mathrm{~mm}$ from the main loop of the CIP model system, and cleaned in the installation. Tap water, without the addition of any detergent, was used as the cleaning agent. A basic assumption was the similar adhesion efficiency of the spores of each tested strain in different experimental repeats (since the spores were obtained using previously validated experimental procedures [21]). The cleaning effect was evaluated by comparing the number of viable spores (attached to the sampling plates), before and after cleaning. The results represent the means and standard deviations (SD) of two independent biological experiments, performed in triplicate. * Statistically significant difference $(p<0.05)$ between the reduction in the viable spore counts of a given sample and the reduction in the spore counts for B. subtilis 3610 (control).

Next, we wanted to test the persistence of the examined Bacillus strains against the chemical effect of the commercial cleaning solutions. Since the chemical effect of the cleaning agents is less dependent on the flow turbulence, it was decided to simplify our experimental system to a lab-scale cleaning test (hereinafter referred to as the laboratory system). We first confirmed the validity of this system by comparing the strains' ability to withstand a mechanical effect. Importantly, the dairy-associated Bacillus demonstrated an enhanced resistance to water circulation (by $0.6-0.7 \log$ ), compared to B. subtilis 3610, also during the cleaning tests performed in the laboratory system (Figure S1). A strong correlation between the results obtained in the two differently designed experimental systems indicates the reliability of the approach used.

\subsection{Dairy-Associated Bacillus Isolates Demonstrate an Enhanced Resistance to Commercial Cleaning Agents during CIP Procedures}

Next, we evaluated the susceptibility to commercial cleaning agents of two selected dairy-associated isolates, B. paralicheniformis S127 and B. licheniformis MS310, which demonstrated the highest amount of EPS surrounding biofilm bacteria, according to a relative fluorescence analysis, in comparison to B. subtilis 3610 (Table S1). Consequently, we performed cleaning procedures using six different alkaline detergents, caustic soda $(\mathrm{NaOH})$ and sodium hypochlorite $(\mathrm{NaOCl})$ at concentrations recommended by the manufacturers. It was found that B. licheniformis MS310, as well as B. paralicheniformis S127, were more resistant to the tested solutions (up to 2.3 and $0.76 \log$, respectively), compared to B. subtilis 3610 (Figure 3). Interestingly, B. subtilis 3610 was particularly susceptible to agents I, M, D and $\mathrm{H}$, whereas B. paralicheniformis S127 was highly persistent to cleaning with agent $\mathrm{H}$ and $\mathrm{NaOH}$, but similarly susceptible to solutions I, $\mathrm{M}$ and $\mathrm{F}$ as B. subtilis 3610. B. lichenifomis MS310 was exceedingly resistant to treatment by the examined solutions, especially to agents $\mathrm{I}, \mathrm{M}$ and $\mathrm{H}$ (Figure 3). 


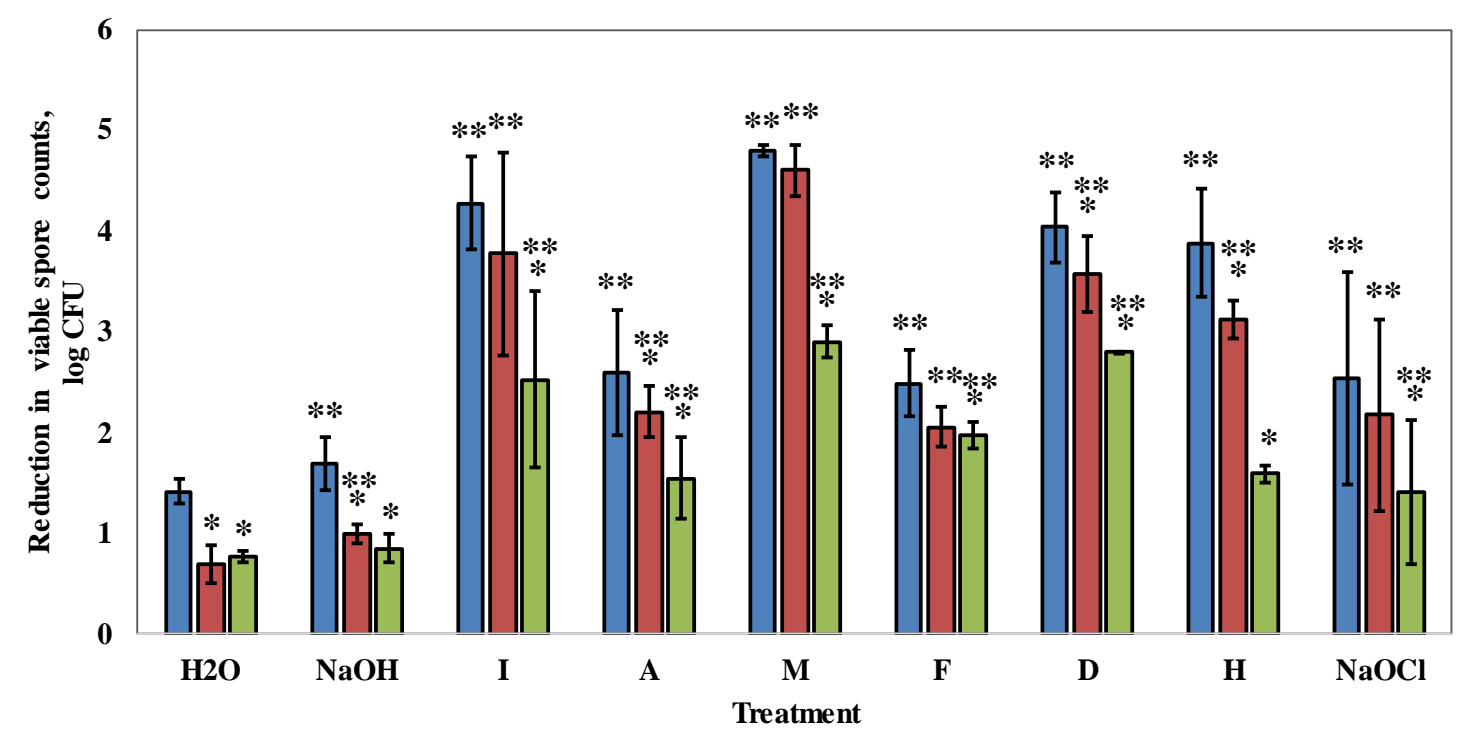

$\square$ B. subtilis $3610 \quad \square$ B. paralicheniformis S127 $\square$ B. licheniformis MS310

Figure 3. Effect of commercial cleaning agents on the removal of the biofilm-derived spores of the dairy-associated Bacillus in the simplified laboratory system. Sampling plates, each maintaining approximately 2 million spores of the tested Bacillus strains, were cleaned in the laboratory system. Caustic soda, sodium hypochlorite and the following cleaning solutions-I, A, M, F, D and H (compositions and dosages are described in Methods)—were used as the cleaning agents. The cleaning effect was evaluated by comparing the numbers of viable spores (attached to sampling plates), before and after cleaning. The results represent the means and standard deviation (SD) of two independent biological experiments, performed in triplicate. * Statistically significant difference $(p<0.05)$ between the reduction in the viable spore counts in a given sample and the reduction in the spore counts for B. subtilis 3610 (control). ${ }^{* *}$ Statistically significant difference $(p<0.05)$ between the reduction in the viable spore counts, after treatment with a given cleaning agent, and the reduction in the spore counts for the same strain, after incubation with tap water.

As indicated in the previous study [21], the biofilm removal effect of a cleaning agent includes both the mechanical effect of the liquid circulation and the chemo-biological effect from the active components, present in the agent. To gain greater insight into the mode of action of the examined solutions, we calculated their chemo-biological effect in relation to the biofilm-derived spores of the tested strains. As shown in Figure S2, B. lichenifomis MS310 was significantly more resistant to the chemo-biological effect of the examined solutions, compared to the other strains. At the same time, in most cases, B. paralichenifomis S127 was equally susceptible to the chemo-biological effect, compared to 3610. This indicates that the tested strains have varying degrees of resistance to the mechanical and chemo-biological effects of cleaning agents. Thus, the low susceptibility of MS310 to the examined solutions results from the increased resistance both to their mechanical and chemo-biological effect (Figure S3). In the case of S127, a high resistance to the majority of the tested solutions (NaOH, I, F, D) is caused mainly by the low susceptibility to the mechanical removal of spores, while the persistence to agents $\mathrm{A}$ and $\mathrm{H}$ results from a reduced sensitivity to both the mechanical and chemo-biological impacts (Figure 3; Figure S3).

\subsection{Dairy-Associated Bacillus Isolates Demonstrate an Enhanced Resistance to the Disinfecting Effect of the Tested Agents}

Primarily, we determined the ability of the tested agents to remove surface-attached spores, without affecting the viability (cleaning effect) and/or inactivating the spores (disinfecting effect). For this, spore suspensions were incubated with each of the tested agents under the conditions of the laboratory system. We found that the examined agents had different influences on the viability of the 
biofilm-derived spores of the tested strains (Figure 4). Thus, solutions D and M notably reduced the spore counts of B. subtilis 3610, after $10 \mathrm{~min}$ of incubation (Figure 4); there was a $0.5 \log$ reduction in the viable spores for S127, after incubation with solution I; while none of the tested solutions affected the viability of the MS310 spores. Interestingly, $\mathrm{NaOCl}$, commonly used as a disinfecting agent, did not influence the viability of the tested strains at the examined concentration (the dosage widely used in industrial cleaning agents; Figure 4).

B. subtilis 3610

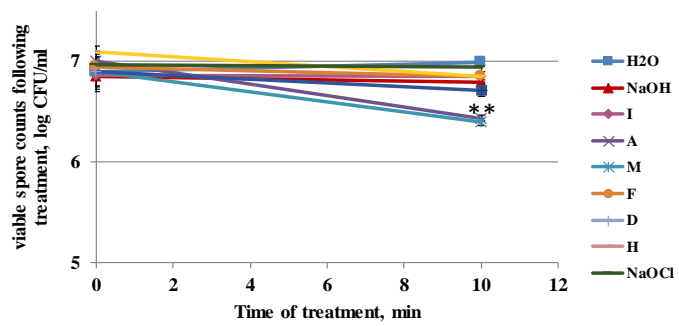

B. paralicheniformis $\mathbf{S 1 2 7}$

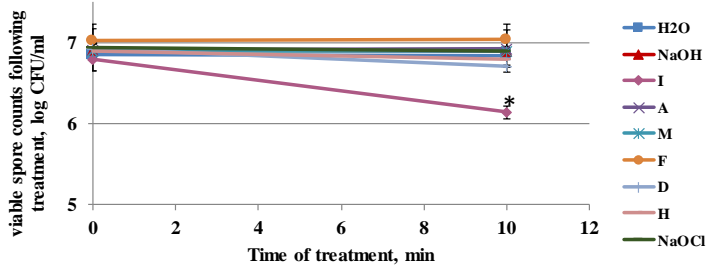

B. licheniformis MS310

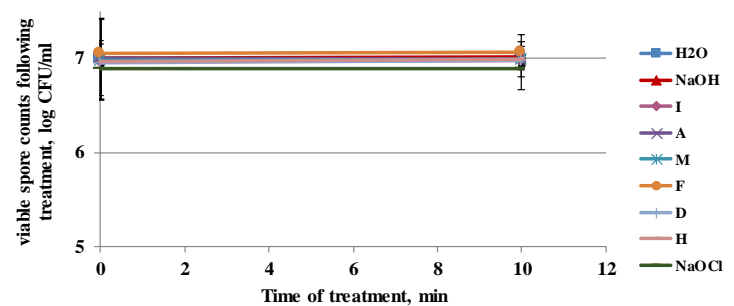

Figure 4. Effect of the examined cleaning agents on the viability of the biofilm-derived spores of the tested Bacillus strains. Caustic soda, sodium hypochlorite, and different cleaning solutions-I, A, M, F, D, and H (compositions are described in Methods)—were added to the tubes, with spore suspension of the tested Bacillus isolates. Spore suspension, without any detergent, was used as the control. The effect on spore viability was evaluated by comparing the numbers of viable spores in the control and after the treatment with the tested agents (following $10 \mathrm{~min}$ of incubation at $50{ }^{\circ} \mathrm{C}$, $250 \mathrm{rpm}$ ). The results represent the means and standard deviation (SD) of two independent biological experiments, performed in duplicate. ${ }^{*}$ Statistically significant difference $(p<0.05)$ between the viable spore counts in a given sample versus the spore counts after cleaning with water (control).

Next, we determined a correlation between the cleaning and disinfecting effects of the tested detergents. Thus, we defined the ability of a cleaning agent to reduce the number of viable spores after 10 min of a cleaning cycle, as a disinfecting effect. We compared the percentage of the disinfecting effect to the total chemo-biological effect of a cleaning agent (taken as $100 \%$ ). The difference between the total chemo-biological effect of the tested agent and the disinfecting effect was defined as the cleaning effect [21]. As can be inferred from Figure 5, the ratio between the cleaning and disinfecting effects of the examined detergents differed for the tested strains. Thus, the removal of the MS310 spores was due solely to the cleaning effect of the tested solutions. B. paralicheniformis S127 was significantly more resistant to the disinfecting effect of agents $\mathrm{A}, \mathrm{M}, \mathrm{F}, \mathrm{H}$, and $\mathrm{NaOH}$, compared to $B$. subtilis 3610, but much more susceptible to the disinfecting effect of solution I (Figure 5). Overall, the chemo-biological effect of the tested agents was mostly due to the removal of surface-attached spores (cleaning effect) and not to disinfecting. 


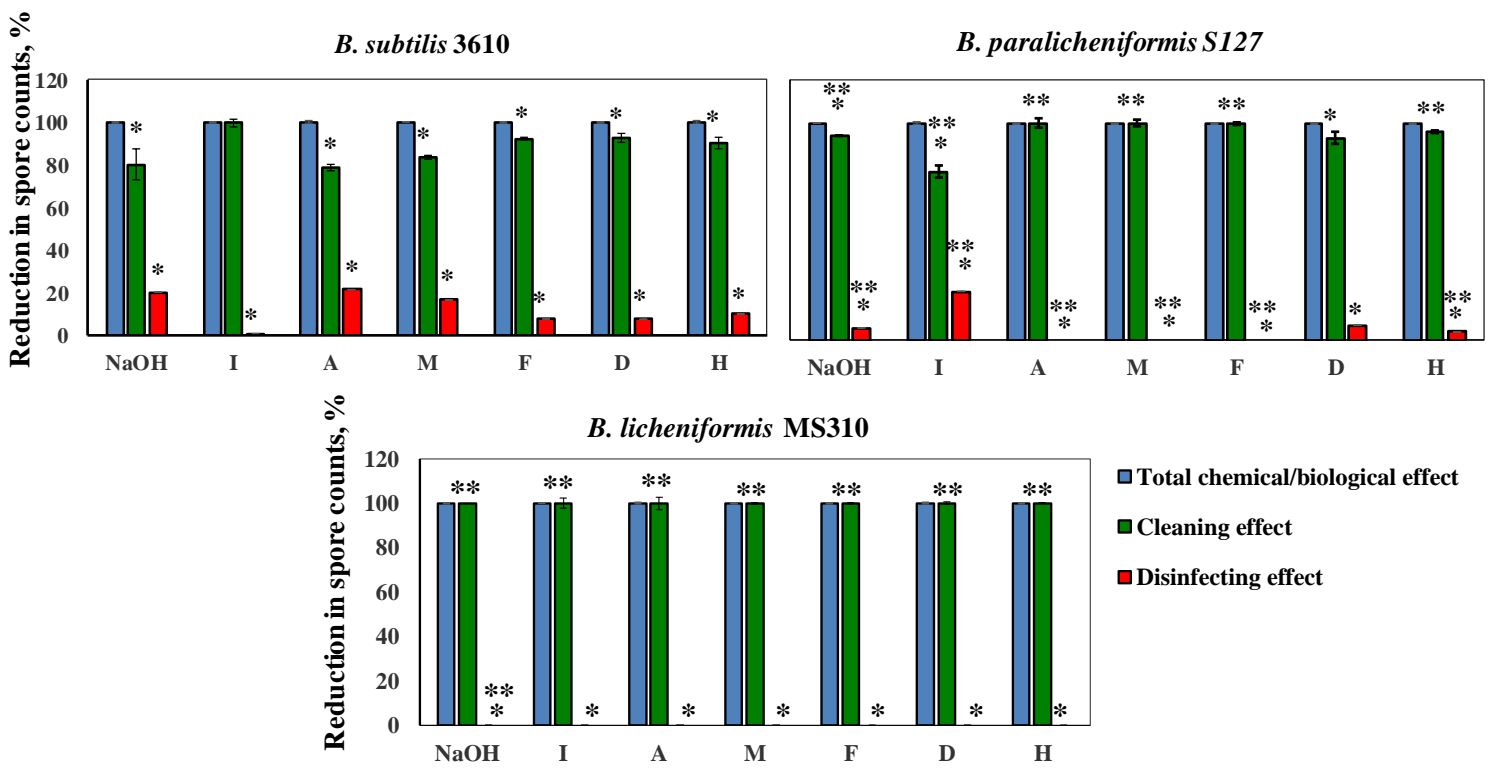

Figure 5. Correlation between the cleaning and disinfecting effects of the examined agents for each tested strain. Caustic soda and different cleaning solutions-I, A, M, F, D, and H (compositions are described in Methods) — were added to the tubes, with spore suspension, of the tested Bacillus isolates and incubated for $10 \mathrm{~min}$ at $50^{\circ} \mathrm{C}, 250 \mathrm{rpm}$. The ability of a cleaning agent to reduce the number of viable spores was defined as the disinfecting effect. The percentage of the disinfecting effect was compared to the total chemical/biological effect of a cleaning agent (taken as $100 \%$ ). The difference between the total chemical/biological effect of a cleaning agent and the disinfecting effect was defined as the cleaning effect. The results represent the means and standard deviation (SD) of two independent biological experiments, performed in duplicate. * Statistically significant difference $(p<0.05)$ between the reduction in the spore counts due to the cleaning or disinfecting effects versus the total chemo-biological effect of a tested agent. ${ }^{* *}$ Statistically significant difference $(p<0.05)$ between the reduction in the viable spore counts in a given sample and the reduction in the spore counts for B. subtilis 3610 (control).

\section{Discussion}

It becomes increasingly clear that biofilm formation by Bacillus species can facilitate their survival in the dairy environment $[11,21]$. Our current study investigated the effect of CIP procedures on strong biofilm-forming dairy Bacillus, compared to the non-dairy B. subtilis 3610, using differently designed model systems. As in our previous study [21], we used biofilm-derived spores to simulate the type of hygiene problem common in practice. Thus, similarly to actual dairy biofilm, biofilm-derived spores combine the presence of biofilm matrix [21] and a high content of spores [29,30]. Moreover, the resistance of vegetative cells/spores to cleaning and disinfection can be greatly enhanced by the presence of EPS [21,31]. At the same time, the presence of spores within the Bacillus biofilm may also modify biofilm properties, e.g., interaction forces [12].

In the current study, two model systems were used to ensure that the enhanced resistance of the dairy isolates to cleaning procedures is observed under different experimental conditions, which are relevant to the industrial CIP systems. Moreover, the design of the CIP system, employed in our previous study does not allow for the evaluation of the disinfecting effect of the cleaning agents on Bacillus spores directly in this system [21]. The laboratory system, developed in this study, provides sufficient conditions both for determining the mechanical, chemo-biological and disinfecting effects of the cleaning agents.

A first notable finding of the study was the enhanced resistance of the dairy Bacillus to the mechanical effect of liquid circulation. Thus, the most expressed difference in cleaning susceptibility between the dairy-associated strains and B. subtilis 3610 was observed at high levels of turbulence (35- and 125-mm T-junctions, CIP model system; Figure 2). In the case of a lower turbulence (275-mm 
T-junction), the difference between the dairy Bacillus isolates and the non-dairy strain is markedly decreased, and for some strains, it was insignificant (Figure 2). These results suggest that the protective effect of Bacillus biofilm matrix is most strongly expressed under a high turbulence of liquid flow. Previous studies demonstrate that a high turbulence may facilitate the removal of surface-attached bacteria [21,32-34], but may also increase the rate of attachment by bringing the microbial cells and the substrate in close proximity [35]. Thus, biofilm formation by the dairy-associated Bacillus can be detrimental not only in so-called "dead legs" (equipment details, in which the flow of liquid is significantly less turbulent), but also in main pipelines.

Furthermore, we showed that the biofilm-derived spores of the dairy Bacillus isolates are much more resistant to commercial cleaning agents, compared to B. subtilis 3610. Presumably, the causes of this resistance differ between the tested strains. Thus, the biofilm-derived spores of MS310 are, apparently, less susceptible both to the mechanical and chemo-biological effects of the employed solutions (Figures S2 and S3). At the same time, B. paralicheniformis S127 has the highest resistance to the mechanical removal of spores but shows a variable susceptibility to the chemo-biological effect of the tested agents.

As shown in our previous study [21], the chemo-biological effect of cleaning agents comprises a disinfecting effect (inactivating bacteria) and/or removal of them from the surfaces of dairy equipment (cleaning effect). According to our results, the dairy Bacillus isolates are significantly less susceptible to the disinfecting effect of the tested agents, compared to the non-dairy strain (except solution I in the case of S127; Figure 4; Figure 5). The observed differences in the mechanical and chemo-biological effects between the tested strains might be explained by the dissimilarities in the biofilm structure. For instance, a correlation between colony biofilm phenotype of the tested strains, and their resistance to the cleaning procedures, was observed (Figure 1). Thus, the dairy-associated Bacillus, characterized by a mucoid biofilm phenotype, were less susceptible to mechanical and chemo-biological effects during the CIP procedures. Since biofilm matrix components can be responsible for binding and/or neutralizing detergents and antimicrobial agents [36,37], differences in the matrix structure/composition can lead to differences in cleaning and/or disinfection susceptibility. Thereby, the biofilm matrix composition was shown to affect the susceptibility of food-associated staphylococci to cleaning and disinfection agents, with polysaccharide matrix-producing strains being more resistant to the lethal effect of benzalkonium chloride [38]. Likewise, the efficiency of monochloramine disinfection was dependent on the quantity and composition of EPS in Pseudomonas biofilms. Protein-based EPS-producing P. putida was less sensitive to monochloramine than polysaccharide-based EPS-producing P. aeruginosa, since monochloramine had a selective reactivity with proteins over polysaccharides [39]. According to Bridier et al. (2011) [40], the biofilm of the P. aeruginosa clinical isolate, in which a high delay of benzalkonium chloride penetration is recorded, was characterized by a large quantity of proteinacious matrix. Moreover, the authors report that, in P. aeruginosa, resistance to antimicrobial agents is intimately related to the inherent three-dimensional organization of cells into the exopolymeric matrix. Therefore, the low sensitivity of the dairy Bacillus isolates to the CIP procedures (compared to B. subtilis 3610) may be connected to differences in the structure/composition of the biofilm matrix.

Importantly, mucoid colony formation, observed for the dairy Bacillus isolates, was viewed as a hallmark of poly- $\gamma$-glutamic acid (PGA) production in multiple previous studies $[17,18]$. Significant production of PGA could result in a stronger attachment to surfaces due to its adhesive properties [41]. To this end, PGA-overproducing derivatives of B. subtilis 3610 (B. subtilis YC295 and B. subtilis YY54) were significantly more resistant to the mechanical effect of water circulation, compared to the wild type (Figure 6C). Notably, biofilm colonies of these mutant strains were more mucoid, compared to the WT (Figure 6A). Moreover, the biofilm-derived spores of PGA-overproducing B. subtilis were surrounded by higher amounts of proteinaceous extracellular matrix, which resembles the tested dairy Bacillus isolates (Figure 6B). Therefore, the presence of PGA in the biofilm matrix of the examined bacterial strains may be one of the factors enhancing resistance to the CIP procedures. 
We believe that the role of PGA and other presumptive EPS components of the dairy-associated Bacillus in relation to cleaning and disinfecting agents is an important subject for further investigation.

Relatively low cleaning and, especially, disinfecting effects of the tested solutions (Figure 5) might lead to undesirable implications regarding the hygiene level in dairy environments. For instance, the rapid recovery of biofilms after inappropriate disinfectant treatment is often observed. This may be due to the re-growth of surviving cells, residual biofilm, providing a conditioning layer for further cell attachment, or the selection of resistant microorganisms that survive and thrive after antimicrobial treatment [5]. In addition, biofilm cells exposure to low (sub-lethal) concentrations of disinfecting compounds, including chlorine-based detergents, can stimulate further biofilm development [10,42,43]. Therefore, we speculate that the composition of commercial CIP agents should be revised and evaluated under the experimental conditions suggested in this study.

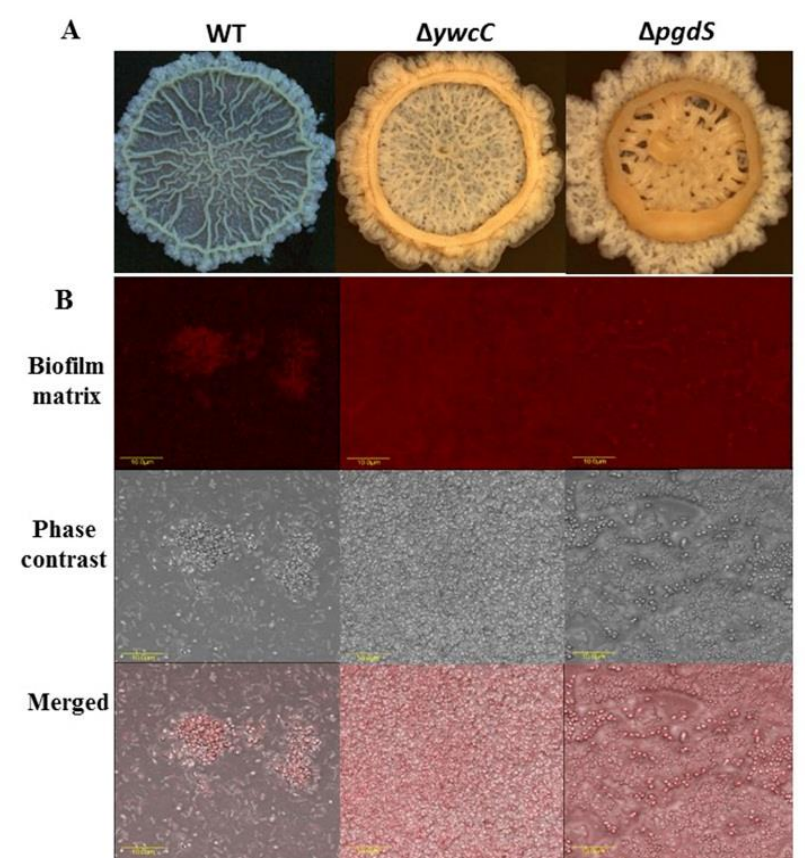

C

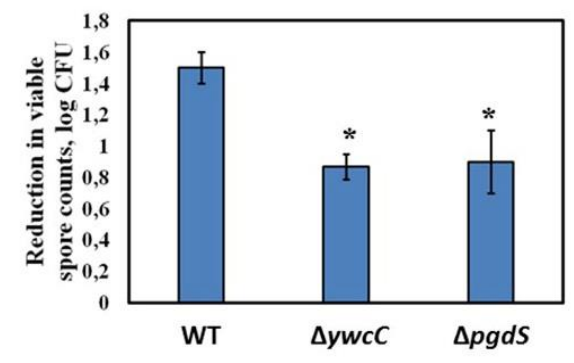

Figure 6. PGA-overproducing derivatives of B. subtilis 3610 exhibit increased resistance to the CIP procedures due to enhanced biofilm formation. (A) Colony biofilm formation by the tested Bacillus strains in the biofilm-promoting medium, LBGM. The images were taken using a stereoscopic microscope (Zeiss Stemi 2000-C; Carl Zeiss, Gottingen, Germany). (B) Biofilm-derived spores of the PGA-overproducing B. subtilis strains are surrounded by high amounts of extracellular matrix. Protein components of the biofilm matrix were stained red. The samples were analyzed using a confocal laser scanning microscope (CSLM, Olympus, Japan). Scale: $10 \mu \mathrm{m}$. (C) The effect of water circulation on the removal of biofilm-derived spores of the PGA-overproducing derivatives of B. subtilis 3610 in the laboratory CIP system. * Statistically significant difference $(p<0.05)$ between the reduction in the viable spore counts in a given sample and the reduction in the spore counts for B. subtilis 3610 (control).

\section{Conclusions}

We demonstrated in this study that the dairy-associated Bacillus isolates are characterized by an enhanced resistance to different aspects of the CIP procedures, such as the mechanical, chemo-biological, and disinfecting effects, compared to the non-dairy Bacillus. Such increased resistance can be attributed to robust biofilm formation by the tested dairy Bacillus. The results of the study underline the importance of revising the composition of commercial cleaning agents and evaluating their efficiency in relation to strong biofilm-forming bacteria, relevant to industrial conditions. To this end, the biofilm-derived spores of the dairy-associated Bacillus, examined in this study, can be used as an appropriate model for assessing and refining the CIP procedures. 
Supplementary Materials: The following are available online at http://www.mdpi.com/2304-8158/8/4/134/s1, Figure S1: Effect of the cleaning procedure with tap water on removal of the biofilm-derived spores of the dairy-associated Bacillus in the simplified laboratory system, Figure S2: Chemo-biological effect of the commercial cleaning agents on removal of the biofilm derived spores in the laboratory CIP system, Figure S3: Correlation between mechanical and chemo-biological effect of the examined agents in relation to the removal of the biofilm derived spores in the laboratory CIP system, Table S1: Relative quantity of the matrix, surrounding biofilm-derived spores of the dairy-associated Bacillus isolates and B. subtilis 3610.

Author Contributions: Conceptualization, I.O. and M.S.; methodology, I.O.; investigation, I.O. and T.P.; data curation, I.O.; writing-original draft preparation, I.O.; writing-review \& editing, M.S.; supervision, M.S.; funding acquisition, M.S.

Acknowledgments: We thank Doron Steinberg from The Hebrew University of Jerusalem for the helpful discussions. We thank Golan Yakov, Avraham Harel and Eduard Belausov for excellent technical assistance. We are also grateful to Yulia Kroupitski, Rama Falk and Adin Shwimmer for their supportive suggestions and discussions. This work was partially supported by the Israel Dairy Board [grant number 4210343].

Conflicts of Interest: The authors declare no conflict of interest.

\section{References}

1. Ivy, R.A.; Ranieri, M.L.; Martin, N.H.; den Bakker, H.C.; Xavier, B.M.; Wiedmann, M.; Boor, K.J. Identification and Characterization of Psychrotolerant Sporeformers Associated with Fluid Milk Production and Processing. Appl. Environ. Microbiol. 2012, 78, 1853-1864. [CrossRef]

2. Ranieri, M.L.; Huck, J.R.; Sonnen, M.; Barbano, D.M.; Boor, K.J. High temperature, short time pasteurization temperatures inversely affect bacterial numbers during refrigerated storage of pasteurized fluid milk. J. Dairy Sci. 2009, 92, 4823-4832. [CrossRef] [PubMed]

3. Kumar, C.G.; Anand, S.K. Significance of Microbial Biofilms in Food Industry: A Review. Int. J. Food Microbiol. 1998, 42, 9-27. [CrossRef]

4. Bremer, P.J.; Fillery, S.; McQuillan, A.J. Laboratory Scale Clean-In-Place (CIP) Studies on the Effectiveness of Different Caustic and Acid Wash Steps on the Removal of Dairy Biofilms. Int. J. Food Microbiol. 2006, 106, 254-262. [CrossRef] [PubMed]

5. Flint, S.H.; Bremer, P.J.; Brooks, J.D. Biofilms in Dairy Manufacturing Plant-Description, Current Concerns and Methods of Control. Biofouling 1997, 11, 81-97. [CrossRef]

6. Pasvolsky, R.; Zakin, V.; Ostrova, I.; Shemesh, M. Butyric Acid Released during Milk Lipolysis Triggers Biofilm Formation of Bacillus species. Int. J. Food Microbiol. 2014, 181, 19-27. [CrossRef] [PubMed]

7. Sharma, M.; Anand, S.K. Bacterial Biofilm on Food Contact Surfaces: A Review. J. Food Sci. Technol. 2002, 39, 573-593.

8. Sharma, M.; Anand, S.K. Biofilms Evaluation as an Essential Component of HACCP for Food/Dairy Processing Industry-A Case. Food Control 2002, 13, 469-477. [CrossRef]

9. Sharma, M.; Anand, S.K. Characterization of Constitutive Microflora of Biofilms in Dairy Processing Lines. Food Microbiol. 2002, 19, 627-636. [CrossRef]

10. Burgess, S.A.; Lindsay, D.; Flint, S.H. Thermophilic Bacilli and their Importance in Dairy Processing. Int. J. Food Microbiol. 2010, 144, 215-225. [CrossRef] [PubMed]

11. Shaheen, R.; Svensson, B.; Andersson, M.A.; Christiansson, A.; Salkinoja-Salonen, M. Persistence strategies of Bacillus cereus spores isolated from dairy silo tanks. Food Microbiol. 2010, 27, 347-355. [CrossRef] [PubMed]

12. Ryu, J.H.; Beuchat, L.R. Biofilm Formation and Sporulation by Bacillus cereus on a Stainless Steel Surface and Subsequent Resistance of Vegetative Cells and Spores to Chlorine, Chlorine Dioxide, and a Peroxyacetic Acid-Based Sanitizer. J. Food Prot. 2005, 68, 2614-2622. [CrossRef]

13. Wijman, J.G.; de Leeuw, P.P.; Moezelaar, R.; Zwietering, M.H.; Abee, T. Air-liquid Interface Biofilms of Bacillus cereus: Formation, Sporulation, and Dispersion. Appl. Environ. Microbiol. 2007, 73, 1481-1488. [CrossRef] [PubMed]

14. Faille, C.; Benezech, T.; Blel, W.; Ronse, A.; Ronse, G.; Clarisse, M.; Slomianny, C. Role of Mechanical vs. Chemical Action in the Removal of Adherent Bacillus Spores during CIP Procedures. Food Microbiol. 2013, 33, 149-157. [CrossRef] [PubMed]

15. Branda, S.S.; Gonzalez-Pastor, J.E.; Ben-Yehuda, S.; Losick, R.; Kolter, R. Fruiting Body Formation by Bacillus subtilis. Proc. Natl. Acad. Sci. USA 2001, 98, 11621-11626. [CrossRef] [PubMed] 
16. Morikawa, M.; Kagihiro, S.; Haruki, M.; Takano, K.; Branda, S.; Kolter, R.; Kanaya, S. Biofilm Formation by a Bacillus subtilis Strain that Produces Gamma-Polyglutamate. Microbiol. Sgm 2006, 152, 2801-2807. [CrossRef]

17. Stanley, N.R.; Lazazzera, B.A. Defining the Genetic differences Between Wild and Domestic Strains of Bacillus subtilis that Affect Poly-gamma-DL-glutamic Acid Production and Biofilm Formation. Mol. Microbiol. 2005, 57, 1143-1158. [CrossRef]

18. Yu, Y.Y.; Yan, F.; Chen, Y.; Jin, C.; Guo, J.H.; Chai, Y.R. Poly-gamma-Glutamic Acids Contribute to Biofilm Formation and Plant Root Colonization in Selected Environmental Isolates of Bacillus subtilis. Front. Microbiol. 2016, 7, 1811. [CrossRef]

19. Midelet, G.; Carpentier, B. Impact of Cleaning and Disinfection Agents on Biofilm Structure and on Microbial Transfer to a Solid Model Food. J. Appl. Microbiol. 2004, 97, 262-270. [CrossRef]

20. Simoes, M.; Simoes, L.C.; Vieira, M.J. A Review of Current and Emergent Biofilm Control Strategies. Lwt-Food Sci. Technol. 2010, 43, 573-583. [CrossRef]

21. Ostrov, I.; Harel, A.; Bernstein, S.; Steinberg, D.; Shemesh, M. Development of a Method to Determine the Effectiveness of Cleaning Agents in Removal of Biofilm Derived Spores in Milking System. Front. Microbiol. 2016, 7, 1498. [CrossRef] [PubMed]

22. Zottola, E.A.; Sasahara, K.C. Microbial Biofilms in the Food-Processing Industry-Should They Be a Concern. Int. J. Food Microbiol. 1994, 23, 125-148. [CrossRef]

23. Faille, C.; Fontaine, F.; Benezech, T. Potential Occurrence of Adhering Living Bacillus Spores in Milk Product Processing Lines. J. Appl. Microbiol. 2001, 90, 892-900. [CrossRef] [PubMed]

24. Ostrov, I.; Sela, N.; Belausov, E.; Steinberg, D.; Shemesh, M. Adaptation of Bacillus Species to Dairy Associated Environment Facilitates their Biofilm Forming Ability. Food Microbiol. 2019. [CrossRef]

25. Ostrov, I.; Sela, N.; Freed, M.; Khateb, N.; Kott-Gutkowski, M.; Inbar, D.; Shemesh, M. Draft Genome Sequence of Bacillus licheniformis S127, Isolated from a Sheep Udder Clinical Infection. Genome Announc. 2015, 3. [CrossRef] [PubMed]

26. Shemesh, M.; Chai, Y.R. A Combination of Glycerol and Manganese Promotes Biofilm Formation in Bacillus subtilis via Histidine Kinase KinD Signaling. J. Bacteriol. 2013, 195, 2747-2754. [CrossRef] [PubMed]

27. Bridier, A.; Tischenko, E.; Dubois-Brissonnet, F.; Herry, J.M.; Thomas, V.; Daddi-Oubekka, S.; Waharte, F.; Steenkeste, K.; Fontaine-Aupart, M.P.; Briandet, R. Deciphering Biofilm Structure and Reactivity by Multiscale Time-Resolved Fluorescence Analysis. Bact. Adhes. Chem. Biol. Phys. 2011, 715, 333-349. [CrossRef]

28. Vlamakis, H.; Chai, Y.R.; Beauregard, P.; Losick, R.; Kolter, R. Sticking Together: Building a Biofilm the Bacillus subtilis Way. Nat. Rev. Microbiol. 2013, 11, 157-168. [CrossRef] [PubMed]

29. Sundberg, M.; Christiansson, A.; Lindahl, C.; Wahlund, L.; Birgersson, C. Cleaning Effectiveness of Chlorine-free Detergents for Use on Dairy Farms. J. Dairy Res. 2011, 78, 105-110. [CrossRef]

30. Faille, C.; Benezech, T.; Midelet-Bourdin, G.; Lequette, Y.; Clarisse, M.; Ronse, G.; Ronse, A.; Slomianny, C. Sporulation of Bacillus spp. within Biofilms: A Potential Source of Contamination in Food Processing Environments. Food Microbiol. 2014, 40, 64-74. [CrossRef] [PubMed]

31. Xue, Z.; Sendamangalam, V.R.; Gruden, C.L.; Seo, Y. Multiple Roles of Extracellular Polymeric Substances on Resistance of Biofilm and Detached Clusters. Environ. Sci. Technol. 2012, 46, 13212-13219. [CrossRef]

32. Leliévre, C.; Antonini, G.; Faille, C.; Bénézech, T. Cleaning-in-place, Modelling of Cleaning Kinetics of Pipes Soiled by Bacillus Spores Assuming a Process Combining Removal and Deposition. Food Bioprod. Process. 2002, 80, 305-311. [CrossRef]

33. Leliévre, C.; Legentilhomme, P.; Legrand, J.; Faille, C.; Bénézech, T. Hygenic Design: Influence of the Local Wall Shear Stress Variations on the Cleanability of a Three-way Valve. Chem. Eng. Res. Des. 2003, 81, 1071-1076. [CrossRef]

34. Wirtanen, G.; Husmark, U.; Mattila-Sandholm, T. Microbial Evaluation of the Biotransfer Potential from Surfaces with Bacillus Biofilms after Rinsing and Cleaning Procedures in Closed Food-Processing Systems. J. Food Prot. 1996, 59, 727-733. [CrossRef]

35. Palmer, J.; Flint, S.; Brooks, J. Bacterial Cell attachment, the Beginning of a Biofilm. J. Ind. Microbiol. Biotechnol. 2007, 34, 577-588. [CrossRef]

36. Mah, T.F.C.; O'Toole, G.A. Mechanisms of Biofilm Resistance to Antimicrobial Agents. Trends Microbiol. 2001, 9, 34-39. [CrossRef]

37. Singh, R.; Ray, P.; Das, A.; Sharma, M. Penetration of Antibiotics through Staphylococcus aureus and Staphylococcus epidermidis Biofilms. J. Antimicrob. Chemother. 2010, 65, 1955-1958. [CrossRef] [PubMed] 
38. Fagerlund, A.; Langsrud, S.; Heir, E.; Mikkelsen, M.I.; Moretro, T. Biofilm Matrix Composition Affects the Susceptibility of Food Associated Staphylococci to Cleaning and Disinfection Agents. Front Microbiol. 2016, 7. [CrossRef] [PubMed]

39. Xue, Z.; Lee, W.H.; Coburn, K.M.; Seo, Y. Selective Reactivity of Monochloramine with Extracellular Matrix Components Affects the Disinfection of Biofilm and Detached Cflusters. Environ. Sci. Technol. 2014, 48, 3832-3839. [CrossRef] [PubMed]

40. Bridier, A.; Dubois-Brissonnet, F.; Greub, G.; Thomas, V.; Briandet, R. Dynamics of the Action of Biocides in Pseudomonas aeruginosa biofilms. Antimicrob. Agents Chemother. 2011, 55, 2648-2654. [CrossRef]

41. Ogunleye, A.; Bhat, A.; Irorere, V.U.; Hill, D.; Williams, C.; Radecka, I. Poly-gamma-glutamic Acid: Production, Properties and Applications. Microbiol. Sgm 2015, 161, 1-17. [CrossRef] [PubMed]

42. Shemesh, M.; Kolter, R.; Losick, R. The Biocide Chlorine Dioxide Stimulates Biofilm Formation in Bacillus subtilis by Activation of the Histidine Kinase KinC. J. Bacteriol. 2010, 192, 6352-6356. [CrossRef] [PubMed]

43. Strempel, N.; Nusser, M.; Neidig, A.; Brenner-Weiss, G.; Overhage, J. The Oxidative Stress Agent Hypochlorite Stimulates c-di-GMP Synthesis and Biofilm Formation in Pseudomonas aeruginosa. Front. Microbiol. 2017, 8 , 2311. [CrossRef] [PubMed]

(C) 2019 by the authors. Licensee MDPI, Basel, Switzerland. This article is an open access article distributed under the terms and conditions of the Creative Commons Attribution (CC BY) license (http://creativecommons.org/licenses/by/4.0/). 